\title{
Maintenance ideal model in Industry 4.0 - A transformation strategy roadmap to readiness factor calculation
}

\author{
Peter POOR ${ }^{1 *}$,Maja TRSTENJAK ${ }^{2}$,Josef BASL ${ }^{1}$ and Tihomir OPETUK ${ }^{2}$ \\ 1 University of West Bohemia, Pilsen, Czech Republic, poorpeter@gmail.com \\ 2 University of Zagreb, Zagreb, Croatia \\ * Correspondence: poorpeter@gmail.com
}

\begin{abstract}
The main purpose of this article is to analyze current status of companies' readiness factor for $4^{\text {th }}$ industrial revolution. Also, we wanted to present a maintenance model idea for a company implementing Industry 4.0. principles. Based on our previous research, firstly machinery maintenance as a phenomenon and its place in a production process is presented. Since every author defines machinery maintenance on its own, we try to choose one, which "fits" best for us. Various types of different approaches to maintenance (based on historical, socio-economic or production factors) are presented here. Also, a correlation between the industrial revolutions and machinery maintenance is shown. In the next part of the article various types of machinery maintenance (according to many different conditions) are presented. Also, based on the previous research there is an obvious correlation between the level of Maintenance and Industrial Revolutions presented. Main part of the article presents an ideal model proposition of maintenance in Industry 4.0. This is based on three main components: hardware, software, humans and organization. This also correlates with the previous research which was made.
\end{abstract}

Keywords: Industry 4.0; machinery; maintenance; predictive; model

JEL Classification: L62;

\section{Introduction}

Every industrial revolution causes technological, socio-economic and cultural changes. Technological aspects include maintenance management. Machinery (machines and equipment) always had one of the main positions in enterprises. Statistically, over $€ 1,500$ billion a year is spent on maintenance, repair and renovation (MRO) only in the EU and over $€ 7,000$ billion globally. Also, jobs are directly linked directly (more than 50 million) and indirectly (more than 150 million) with machinery maintenance. Thus, it is very important to deal with machinery maintenance in industrial environment. The digitalization era we are currently living in has a direct impact on the industry and the market. It creates new competitive environment where the goal is to be the best, where good is not on the satisfactory level anymore (Kotynkova, 2016). The changes are constant and continuous, and they apply to every aspect of the working environment. Maintenance plays a very important role in the digitalization process and in the newly constituted manufacturing processes, because it enables the less time and cost loss regarding the pro-active act. The traditional on-demand maintenance requires the abortion of every current process and has an immediate effect on the entire supply chain. The problem is that the on-demand maintenance cannot be predicted when and how long will occur. The preventive maintenance has been recognized as a significant help within the process, as the maintenance activities are planned ahead and avoid manufacturing process blockages. But this still isn't a guarantee of the time and cost minimization regarding unplanned on-demand maintenance activities. The pro-active and predictive maintenance require high level of digitalization and use advanced predictive analytics that enable the optimum level of activities with as less time waste and 
money loss possible. In this article we try to present the most advanced maintenance up to date, with some clarification of our model.

\section{Methodology}

As it was defined in the previous chapter, there really is a correlation between the improvement of the industrial environment and the new maintenance concept, that is why we want to present a maintenance model idea for a company implementing Industry 4.0. principles, we need to properly define maintenance first. Machinery maintenance was never a factor commonly monitored in companies. Studies show, that a closer look on the maintenance is shown after World War II. Of course, there were some kinds of industrial maintenance earlier (during Industrial revolutions 1-2), but maintenance as a specific key factor in production is carefully observed in 1950s. There are a lot of different approaches and definitions on machinery maintenance, below is a list of few. Maintenance thus, as a "science", can be defined as:

- "Combination of all technical, administrative and managerial actions during the life cycle of an item intended to retain it in, or restore it to, a state in which it can perform the required function" (SS-EN 13306, 2001).

- "The main purpose of maintenance engineering is to reduce the adverse effects of breakdown and to increase the availability at a lower cost, in order to increase performance and improve the dependability level" (Simeu-Abazi and Sassine, 2001, p.268).

- process that the production process needs; it is the primary process where input is transformed in output and Maintenance is a secondary process that helps the first to the achievement of production. (Gits, 1994).

- Maintenance management covers all actions including inspection, adjustments, cleaning, lubrication, testing, and replacement of expendable parts, as necessary to maintain the serviceability of the equipment (API RP 8B 2012).

- maintenance implies all measures that assist to save and re-make the required condition of machinery and equipment. (Bagadia, 2006)

Maintenance has, according to terminology and standards, a direct link to reliability and thus to readiness, under which maintainability and maintenance is ensured. Machinery maintenance, as any other science, also developed depending on the circumstances. There are various types of maintenance. As our previous research indicates, maintenance used can be related to the development of industry. (Poór, Ženíšek, Basl,2019).

The oldest type is simply called reactive maintenance, where after maintenance was carried out only after failure, which could simply prolong machine's useful life. Of course, this brought unplanned breakdowns and possible long machine downtime. Another type was immediate or delayed maintenance, as the machines began to be larger and more complex. We are referring to second industrial revolution, coming of production lines, which operation became more expensive.

Regular inspections and repairs come to play here, maintenance is started being called preventive, and its main goal is to prevent failures. Also, regular inspections and revisions are made by maintenance personnel, which also is under development. Basic perceptions such as hearing, sight and touch of machine operator are used. The basic principles of predictive maintenance (which is another evolution step) are diagnostics and condition monitoring equipment. Now, machines are not repaired at regular intervals but only if the repair is required. This allows us to reduce costs on material, workforce, time and resources.

Proactive maintenance goes even further by identification of the causes of failure by means of technical diagnostics. Reliability-based maintenance is "a procedure to establish maintenance requirements for any physical asset in its operational context." (Jardine, 2006).

Total Productive Maintenance - TPM - is the state-of-the-art philosophy, organization of machine

maintenance in the production process, with a significant share in increasing productivity and eliminating costs. It is a set of maintenance activities performed throughout the lifetime - the existence of 
machines in order to improve their accuracy, reliability, performance and efficiency as well as reducing all possible losses. (Sullivan, et al., 2004)

Since there is a lot of different approaches to machinery maintenance and every author defines maintenance on its own (based on conditions, type of production, resources, technological development), there are a lot of different kinds of "maintenance types". For our purpose, this division according to (Project services, 2017) fits the best.

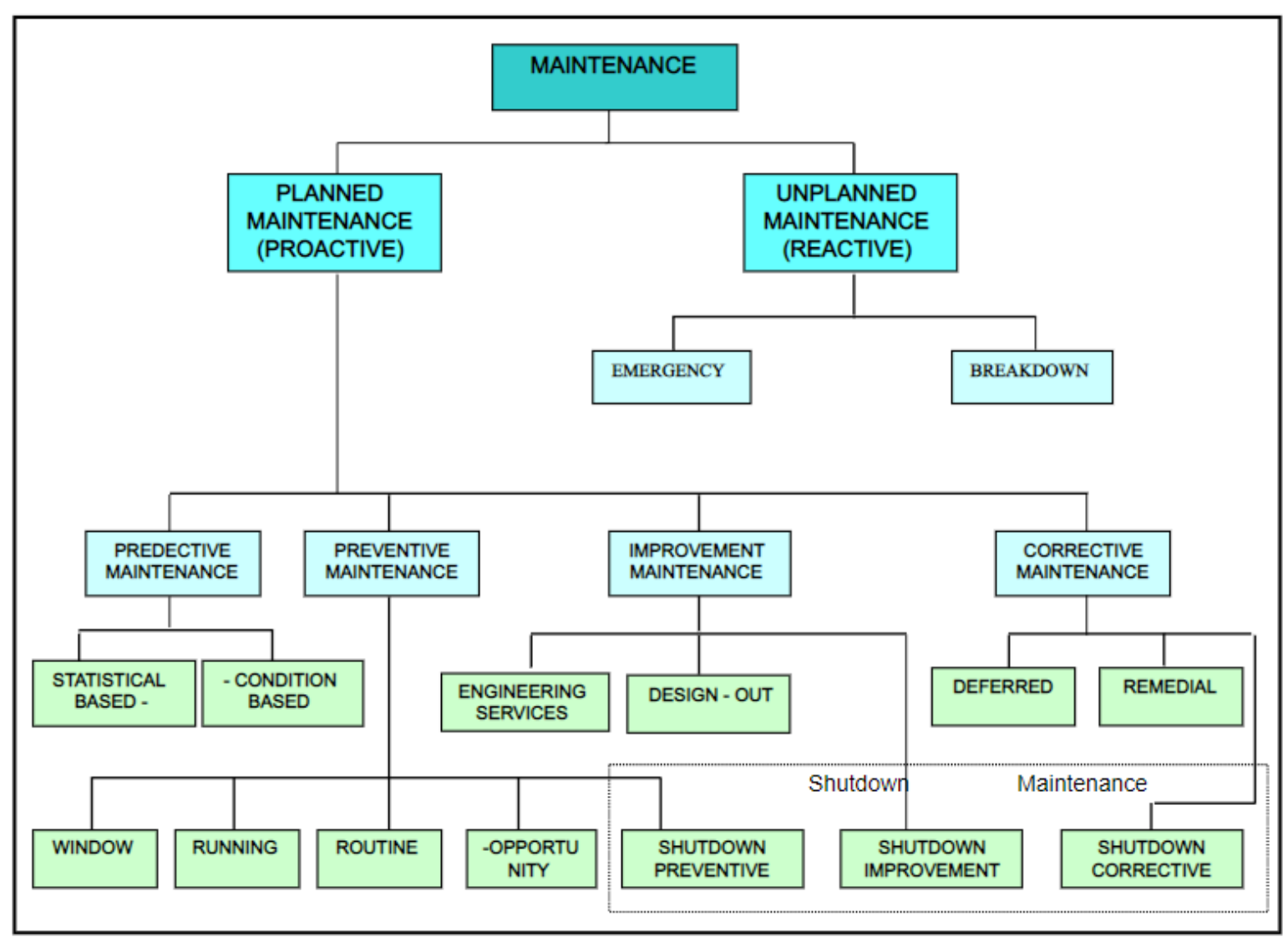

Figure 1 Figure 2: Types of machinery maintenance (Project Services Co. - Quatar, 2017)

As mentioned before, in our previous research we were trying to find a correlation between the industrial revolutions and machinery maintenance.

An English economic historian Arnold Toynbee firstly used the term Industrial Revolution to describe Britain's economic growth from 1760 to 1840. It is defined as "the comparatively sudden and violent change which launches the industrialized society into being, transforming that society in a way which none of the earlier so-called industrial revolutions ever did" (Coleman, D. C. 1956)

The first industrial revolution started in England. One of the main changes was in use of energy sources, forms of transport, information transfer and industrialization of production. There has been a massive increase in labor productivity, which resulted in transformation from the agrarian country into an industrial one. The symbol of the first industrial revolution was a steam engine invented by James Watt in 1765 (Spear, B. 2008). As previously said, we are dealing with machinery maintenance since 1950s. But there were some hints of using "maintenance", in basic forms of breakdown maintenance, when repairs were done only after complete machine breakdown. This strategy of "letting the device work until it goes wrong" was the first that people naturally applied.

The Second Industrial Revolution began about 1870 and was connected to mass production mostly. Assembly lines (Henry Ford for his Model T automobiles factories) and other technological innovations needed new approach to maintenance. Science was suddenly connected to the technology, research results from natural sciences were being applied in industry. Also, from the point of view of machinery, machines became more complex and production grew rapidly. Breakdowns caused higher 
and higher expenses and therefore first attempts of preventive maintenance (also known as planned maintenance) appeared. Preventive maintenance can be characterized as: "Action based on a specific timetable that identifies, avoids or mitigates the decay of component or framework state so in order to maintain or expand its life by means of controlled corruption to an adequate level" (Butler, K. L. 1996). Using this kind of maintenance has several advantages over purely reactive maintenance (higher device efficiency, which will be reflected in savings).

With the Third Industrial Revolution first programmable logic controller, e.g. PLC, was made (Jensen, M. C. 1993). Also automation, electronics and expansion of information technology characterize this era. Productive Maintenance is the most prevalent type of machinery maintenance here, which combines Corrective and Preventive Maintenance with a data-driven, analytical approach, and is performed to increase the broadly economic efficiency of production (Aziz, Iftekhar, Sazedul Karim, and M. Hossain 2012). Maintenance is integrated into the company strategy (TPM), screens the activity of every component and characterizes the outcomes of its failures (RCM), or deals with the assessment of possible causes of device failures. Total productive maintenance and its motto "Protect your machine and take care of it with your own hands." (Legat, V. 2013) relies on machine operators understand them and take care as their "very own".

With the Fourth industrial revolution (which is still happening) predictive maintenance (nowadays also called PdM 4.0) is the highest form of maintenance. By combination of big data analytics and artificial intelligence we try to prevent asset failure by analyzing production data to identify patterns and predict issues before they happen.

To sum up this part of the article, there really is a correlation between the industrial revolutions and machinery maintenance. Table 1 also presents characteristics of four industrial revolutions (from the point of technologies and principles of taking care of industrial equipment), what is described above. We choose only four "main" types of maintenance. Also, the "inspection" row is interesting here, you can see the development from only visual inspection at the beginning, through instrumental inspection to more sophisticated use of technologies, like sensors and predictions nowadays. There is also an inverse correlation between the level of Maintenance and its "main important factor" - Overall Effectivity of Equipment. The more developed maintenance, the higher OEE is. (Poór, Ženíšek, Basl, 2019)

Table 1. Correlation between the level of Maintenance and Industrial Revolutions

\begin{tabular}{|c|c|c|c|c|}
\hline $\begin{array}{l}\text { Industry } \\
\text { revolution }\end{array}$ & Industry 1.0 & Industry 2.0 & Industry 3.0 & Industry 4.0 \\
\hline $\begin{array}{c}\text { Characteristics } \\
\text { of the } \\
\text { industrial } \\
\text { revolution }\end{array}$ & $\begin{array}{l}\text { Mechanization, } \\
\text { steam power, } \\
\text { weaving loom }\end{array}$ & $\begin{array}{c}\text { Mass production, } \\
\text { assembly lines, electrical } \\
\text { energy }\end{array}$ & $\begin{array}{l}\text { Automation, } \\
\text { computers, } \\
\text { electronics }\end{array}$ & $\begin{array}{c}\text { Cyber } \\
\text { Physical } \\
\text { Systems, } \\
\text { IoT, } \\
\text { networks, } \\
\text { cloud, BDA }\end{array}$ \\
\hline $\begin{array}{c}\text { Type of } \\
\text { maintenance }\end{array}$ & $\begin{array}{c}\text { Reactive } \\
\text { maintenance }\end{array}$ & Planned maintenance & $\begin{array}{c}\text { Productive } \\
\text { maintenance }\end{array}$ & $\begin{array}{c}\text { Predictive } \\
\text { maintenance }\end{array}$ \\
\hline Inspection & $\begin{array}{c}\text { Visual } \\
\text { inspection }\end{array}$ & Instrumental inspection & $\begin{array}{c}\text { Sensor } \\
\text { monitoring }\end{array}$ & $\begin{array}{c}\text { Predictive } \\
\text { analysis }\end{array}$ \\
\hline OEE & $<50 \%$ & $50-75 \%$ & $75 * 90 \%$ & $>90 \%$ \\
\hline $\begin{array}{l}\text { Maintenece } \\
\text { teams } \\
\text { reinforcement }\end{array}$ & $\begin{array}{l}\text { Trained } \\
\text { craftsmen }\end{array}$ & Inspectors & $\begin{array}{l}\text { Reliability } \\
\text { engineers }\end{array}$ & $\begin{array}{c}\text { Data } \\
\text { scientists }\end{array}$ \\
\hline
\end{tabular}

\section{Results}

Based on the previous results, we try to propose an ideal model of maintenance in Industry 4.0. Since digitalization and acceptance of Industry 4.0 concept requires more or less radical changes within 
the working environment, the adequate strategy has to be formed in order to create final result that will gain profit in the future. Certain parts of the digital concept have already been achieved within the company, since the market has already started to change and the working environment requires the use of Internet, but not in every company the use of digital methods is yet on the same level. Therefore, some require more and some less changes which require certain level of financial investment. General and complete transformation usually is financially very demanding, that is why the readiness factor of the company has to be calculated accurately before the digital transformation process begins. Not every company nor department requires same level of change, but each has to be compared to the ideal model. Based on previous research results the focus is set on the maintenance for which the ideal model of Industry 4.0 concept is shown on Figure 2.

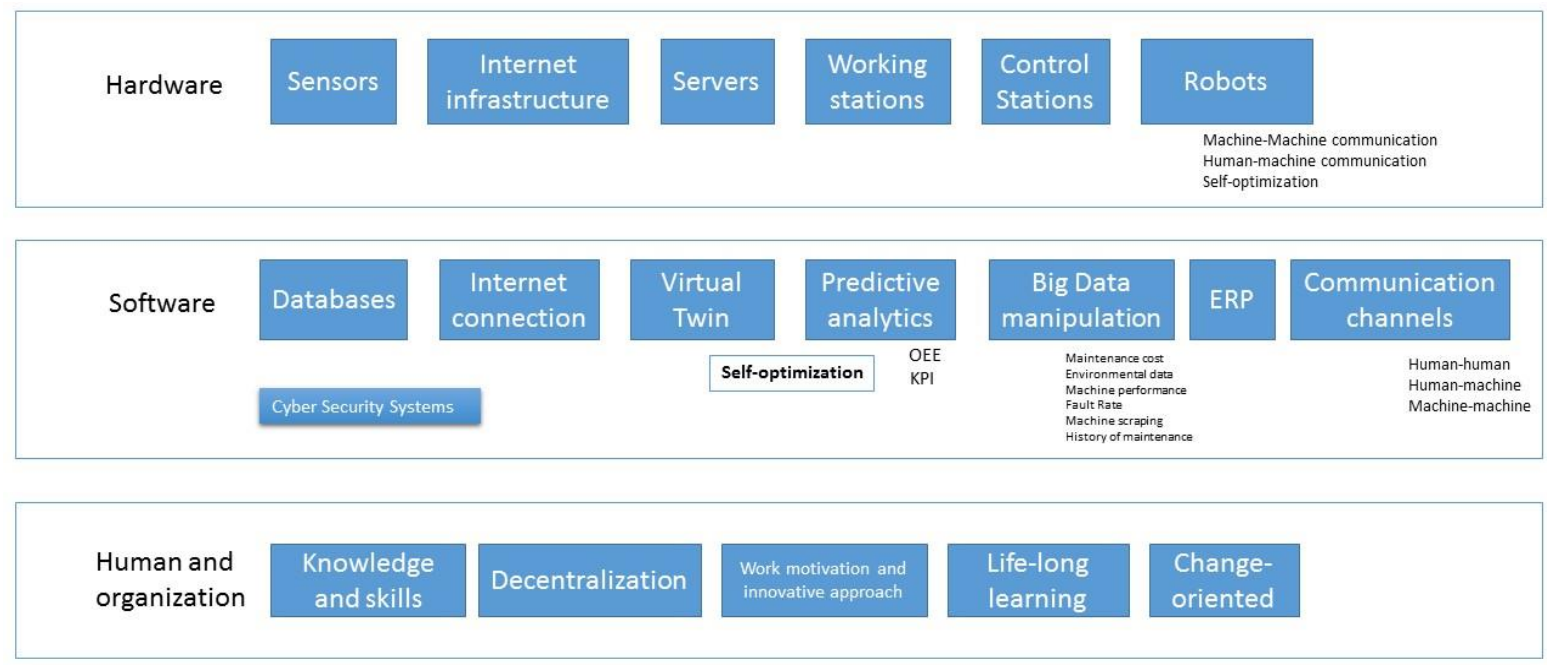

Figure 2Maintenance ideal model in Industry 4.0

The ideal model describes the segments in three major groups - Hardware, Software and Human and Organization. Those are the three major segments of every company and describe the working environment in full. Each segment of the ideal model has to be compared with the current state and use of it in the company, what in the end gives a clear overview where the changes are mostly required. Also, in the future use of the advanced decision support methods, the importance of each segment for the unique case studies can be measured so that the strategic plan can be created in the end.

On the hardware level, there are six segments of the Maintenance 4.0 included. Sensors are the main hardware that enable the collection of the real-time data from the machines (Gregor and et al., 2015) Internet infrastructure enables the distribution of the data collected within the system. State-of-art Internet infrastructure enables fast and accurate data distribution within the company and other parts of the supply chain, if needed. Servers are closely connected to Internet infrastructure, but yet they enable the independence and flexibility of the single company. Working Stations is the hardware present at the manufacturing hall, machines or the single working environments where the final product is physically created. Those require high level of modularity, flexibility and adaptivness for the data collection via sensors (Mihalov, J. et al., 2018). Control Stations are the computers that deal with data analytics and enable the performance of the advanced analytics. Robots are also one of the main segments of the Industry 4.0 (Broum, Šimon, 2019) hardware, within the Maintenance 4.0 they can also have the possibility to assist in the maintenance activities, therefore they have the advanced capacities of machinemachine and machine-human communication so they could be realization of the self-optimization requirements in the real-time.

Software group is defined in $7+1$ segments. Databases and its capacity are important for big data storage and its grouping (Orosz, Sleisz, Z. Á.Tamus, 2015). Internet connection is connected to internet infrastructure which enable the proper connection, which also has to be functioning on the high level. Virtual twin enables the real-time monitoring of the all processes and development of the maintenance plans (Kliment, Trebuňa, 2014) 
In the case of the unplanned events, digital twin enables the easy failure detection and maintenance plan development. Predictive analytics enable the proactive maintenance and are the result of the capacity and the possibilities of the big data manipulation segment. Predictive analytics are implemented in software that can also measure OEE and various KPI that company requires, especially within the maintenance department. Virtual Twin in combination with predictive analytics enables the selfoptimization of the system. (Simon, Broum, 2018).

The complete software unification and the connection of the maintenance department with other departments within the company or the supply chain is enabled with complex, unique and personalized ERP systems. Communication channels have to be highly functioning and flexible, and enable the machine-machine, human-machine and human-human communication. Each of the software segments deal with the challenges of the security issues (Balaz, A. et al. 2018), so that special cyber security systems within the company and the maintenance department are to be developed.

The hardware and software changes aren't sufficient in order to complete digital transformation of the maintenance department in the company. The changes are to happen on the human and organizational level, which could be most challenging in the whole process (Pollák, Tkáč, 2019). That is why the Human and organization group consists of five crucial segments. Change of the working environment requires new knowledge and skills of the worker, that is why they have to be ready to accept and function within new working environment. Their work motivation is also key factor and innovative approach which enables the flexibility that can lead to leading position on the market and, in the maintenance department, shorten the time-loss or the failures in general. Growth of the workers is continuous that is why the company should organize special educational system for its workers. Both workers and the organizational system has to be change-oriented, flexible and modular in order to gain sustainable digital system. Decentralization is also important factor of the Maintenance 4.0, where the decision possibilities are spread horizontally that enable the shorter reaction and action time.

\section{Discussion and conclusions}

There are various readiness level calculation methods already presented in the literature, but the basic framework is universal - the comparison of the current with the ideal state is needed to be concluded and the gap between current and future state is to be detected. Each previously described segments has to be evaluated by its importance by the unique user, therefore the criteria tree with its ponders could be created. Additional segments can also be added, depending of the unique demands of the certain company. Users evaluate current state of each segment, based on the certain evaluation model. The results are then being calculated with previously described maturity model and the readiness level is therefore formed. The importance of priority changes within each segments is then viewable so that the adequate strategic plan for the digital transformation to Maintenance 4.0 can be created. For the future work the use of the new Maintenance 4.0 model in the practice should be tested as well as the transformational process whose monitoring could result in the universal strategic model for wider spectre of industry transformation on their road to complete Industry 4.0 concept.

Acknowledgments: This research was supported by the project SGS-2018-031 Optimizing the parameters of a sustainable production system.

\section{References}

API RP 8B, Recommended Practice for Procedures for Inspections, Maintenance, Repair and Remanufacture of Hoisting Equipment, Seventh Edition, March 2002 (Reaffirmed: August 2012)

Aziz, Iftekhar, Sazedul Karim, and M. Hossain, 2012. Effective implementation of total productive maintenance and impacts on breakdown time and repair \& maintenance-a case study of a printing industry in Bangladesh. Proceedings of the Global Engineering, Science and Technology Conference

Bagadia, Kishan, 2006. Computerized maintenance management systems made easy: how to evaluate, select, and manage CMMS. McGraw-Hill Professional, 2006. ISBN 0071469850, 9780071469852

Balaz, A. et al. 2018. ModSecurity IDMEF module. IEEE World Symposium on Applied Machine Intelligence and Informatics, pp. 43-48, doi: 10.1109/SAMI.2018.8323984) 
Broum T., Šimon M.2019. Preparation of Collaborative Robot Implementation in the Czech Republic. Proceedings of the International Conference on Industrial Engineering and Operations Management (IEOM), Pilsen, Czech Republic

Butler, K. L. 1996. An expert system-based framework for an incipient failure detection and predictive maintenance system. Intelligent Systems Applications to Power Systems, 1996. Proceedings, ISAP'96., International Conference on (pp. 321-326).

Coleman, D. C. 1956. Industrial growth and industrial revolutions. Economica, 23(89), 1-22.

Gits, C. W. 1994. Structuring Maintenance Control Systems. International Journal of Operations E Production Management, 14(7), pp. 5 - 17

Gregor, M., Horejsi, Simon, M. 2015. Case study: Motion capture for ergonomics. Proceedings of the 25th International Business Information Management Association Conference - Innovation Vision 2020: From Regional Development Sustainability to Global Economic Growth, IBIMA 2015, pp. 468-476.

Jardine, A. K. D. L. a. D. B. 2006. A review on machinery diagnostics and prognostics implementing condition-based maintenance. Mechanical systems and signal processing, 20(7), pp. 1483-1510.

Jensen, M. C. 1993. The modern industrial revolution, exit, and the failure of internal control systems. the Journal of Finance, 48(3), 831-880

Kliment, Marek - Trebuňa, Peter. 2014. Simulations as an appropriate way of verifying the efficiency of production variants in the design of production and non-production system. Acta Logistica. 1(4) pp. 17-21. - ISSN 13395629.

Legat, V. 2013. Management and maintenance engineering. Praha: Professional Publishing, ISBN 978-80-7431-1192.

Martin Pollák, Jozef Tkáč. Enterprise information data management system for small manufacturing company. TEM Journal: Technology, Education, Management, Informatics. - Novi Pazar (Srbsko), Association for Information Communication Technology Education and Science, 8(4), pp. 1169-1175, 2019, ISSN 2217-8309.

Mihalov, J. et al. 2018. Potential of Low Cost Motion Sensors Compared to Programming Environments. Acta Polytechnica Hungarica, vol. 15, no. 6, pp. 155-177, doi: 10.12700/APH.15.6.2018.6.9.

Orosz, Tamás, Ádám Sleisz, and Zoltán Ádám Tamus. 2015. Metaheuristic optimization preliminary design process of core-form autotransformers. IEEE Transactions on Magnetics 52(4), pp. 1-10.

Poór, Peter, David Ženíšek, and Josef Basl. (2019): Historical Overview of Maintenance Management Strategies: Development from Breakdown Maintenance to Predictive Maintenance in Accordance with Four Industrial Revolutions." International Conference on Industrial Engineering and Operations Management, Pilsen, Czech Republic, July 23-26, 2019.

Project Services Co. - Quatar, 2017. [Online]. Available at: https://www.pscqatar.com/index.php?page=display_part\&pid=138. [Online].

Simeu-Abazi, Z. a. 2001. Maintenance Integration in Manufacturing Systems: From the Modeling Tool to Evaluation. The International Journal of Flexible Manufacturing Systems,13(2),pp. 267-285

Simon, Michal \& Broum, Tomas. 2018. Layout Calculations Related to Product Insourcing, Proceedings of the 29th DAAAM International Symposium, pp.0312-0318, B. Katalinic (Ed.), Published by DAAAM International, ISBN 978-3-902734-20-4, ISSN 1726-9679, Vienna, Austria DOI: 10.2507/29th.daaam.proceedings.045)

SS-EN 13306, 2001, p.7 - SIS Förlag AB. (2001). "Maintenance terminology - Svensk Standard SS-EN 13306". Stockholm, Sweden.

Sullivan, G. P., Melendez, A. P. \& Pugh, R., 2004. FEMP'S O\&M Best Practices Guide A Guide to Achieving Operational Efficiency. Strategic Planning for Energy and the Environment, 23(4), pp. 40 - 52.

(C) 2019 by the authors. Submitted for possible open access publication under the terms and conditions of the Creative Commons Attribution (CC BY) license (http://creativecommons.org/licenses/by/4.0/). 